\title{
Development of cDNA microarray for expression profiling of estrogen-responsive genes
}

\author{
A Inoue ${ }^{1,2}$, N Yoshida ${ }^{1,3}$, Y Omoto ${ }^{1}$, S Oguchi ${ }^{4}$, T Yamori ${ }^{5}$, R Kiyama ${ }^{2,4}$ and \\ S Hayashi ${ }^{1}$ \\ ${ }^{1}$ Division of Endocrinology, Saitama Cancer Center Research Institute, 818 Komuro, Ina-machi, Kitaadachi-gun, Saitama-ken \\ 362-0806, Japan \\ ${ }^{2}$ Institute of Molecular and Cell Biology (IMCB), Tsukuba Center, National Institute of Advanced Industrial Science and Technology (AIST), \\ AIST Tsukuba Central 6, 1-1, Higashi 1-Chrome, Tshkuba-shi, Ibaraki-ken 305-8566, Japan \\ ${ }^{3}$ Division of Endocrinology, Department of Internal Medicine, University of Tokyo Graduate School of Medicine, 7-3-1, Hongo, Bunkyo-ku, \\ Tokyo 113-0033, Japan \\ ${ }^{4}$ InfoGenes Co. Ltd, Tsukuba, Ibaraki 305-0047, Japan \\ ${ }^{5}$ Department of Molecular Pharmacology, Cancer Chemotherapy Center, Cancer Institute, 1-37-1, Kamiikebukuro, Toshima-ku, Tokyo \\ 170-8455, Japan \\ (Requests for offprints should be addressed to S Hayashi; Email: shin@cancer-c.pref.saitama.jp)
}

\begin{abstract}
Estrogen plays an important role in many physiological events including carcinogenesis and the development of human breast cancer. However, the molecular mechanisms of estrogen signaling in cancers have not been clarified hitherto and accurate therapeutic prediction of breast cancer is earnestly desired. We first carried out estrogen-responsive expression profiling of approximately 9000 genes in estrogen receptor-positive human MCF-7 breast cancer cells. Based on the results, estrogen-responsive genes were selected for production of a custom-made cDNA microarray. Using a microarray consisting of the narrowed-down gene subset, we first analyzed the time course of the estrogen-responsive gene expression profiles in MCF-7 cells, resulting in subdivision of the genes up-regulated by estrogen into early-responsive and late-responsive genes. The expression patterns of several genes were confirmed by Northern blot analysis. We also analyzed the effects of the estrogen antagonists $\mathrm{ICl} 182,780$ and 4-hydroxytamoxifen (OHT) on the estrogen-responsive gene expression profiles in MCF-7 cells. While the regulation of most of the genes by estrogen was completely abolished by $\mathrm{ICI} 182,780$, some genes were partially regulated by estrogen even in the presence of OHT. Furthermore, the estrogen-responsive gene expression profiles of twelve cancer cell lines derived from the breast, ovary, stomach and other tissues were obtained and analyzed by hierarchical clustering including the profiles in MCF-7 cells. Several genes also showed up-regulation or down-regulation by estrogen in cell lines other than MCF-7 cells. The significance of the estrogen-responsive genes identified in these analyses concerning the nature of cancer is discussed.
\end{abstract}

Journal of Molecular Endocrinology (2002) 29, 175-192

\section{Introduction}

Estrogen plays an important role in the biological events in many organs and is especially closely associated with both development and neoplasia of the mammary gland (Pike et al. 1993, Ciocca \& Fanelli 1997, Anderson et al. 1998). In normal and malignant mammary cells, estrogen receptor alpha $(\mathrm{ER} \alpha)$, one of the nuclear receptor transcription factors, is the primary target of estrogen, and the enhanced expression of ER $\alpha$ is one of the most critical events in the development of breast cancer (Hayashi et al. 1997a, Shoker et al. 1999). Hence, the expression status of $\mathrm{ER} \alpha$ is a primary determinant in the anti-hormone therapy of breast cancer using antagonists to ER $\alpha$ such as tamoxifen (McGuire 1978, Lapidus et al. 1988). We have been studying the molecular mechanisms of 
estrogen-dependent breast carcinogenesis, specifically from the viewpoint of regulation of ER $\alpha$ gene expression (Hayashi et al. 1997a, Tanimoto et al. 1999, Yoshida et al. 2000) and functional modulation of ER $\alpha$ (Hayashi et al. 1997b, Saji et al. 2001) in breast cancer cells. For clinical application, however, the assay of $\mathrm{ER} \alpha$ status is not at present completely predictive for responsiveness of the tumors to anti-estrogens; not all tumors of the patients diagnosed as ER-positive respond to anti-hormones.

There are many reports concerning the target genes transcriptionally activated by $\mathrm{ER} \alpha$ such as pS2 (Masiakowski et al. 1982) and cathepsin D (Westley \& Rochefort 1980), but the entire mechanism of the pathway from ER $\alpha$ leading to the proliferation and progression of mammary tumors is far from being completely clarified. Furthermore, another estrogen-signaling pathway independent of nuclear receptors has been postulated (Pietras \& Szego 1977, Nadal et al. 2000). For elucidation of the scheme of estrogen-signaling and improvement of clinical decisions, expression profiling analysis using cDNA microarray technology should be one of the most effective procedures.

Several laboratories have carried out cDNA microarray analysis of breast tumors from patients (Gruvberger et al. 2001, Sørlie et al. 2001, West et al. 2001, van't Veer et al. 2002) and a novel gene whose expression status was highly correlated with the prognosis of patients was identified (Finlin $e t$ al. 2001). There has also been a report concerning gene expression profiling in human ZR75-1 breast cancer cells in the presence of estrogen or estrogen antagonists using oligonucleotide microarray (Soulez \& Parker 2001), and several novel estrogen-responsive genes were identified. Nonetheless, there is little information on how many markers are sufficient and which markers are suitable for accurate prognosis and diagnosis of breast tumors, especially regarding sensitivity to anti-hormone therapy. Microarray systems used in previous reports consisted of several thousand clones and therefore are obviously powerful for basic cancer research, but to use such a microarray glass slide for the diagnosis of each patient is too expensive for clinical application.

In the present report we first analyzed the expression profiles of approximately 9000 genes in human MCF-7 breast cancer cells in response to estrogen. Based on the results, we selected the estrogen-responsive genes in MCF-7 cells and developed custom-made microarray systems consisting of the selected genes. Using the microarray systems, we analyzed the time course of estrogenresponsive gene expression profiles and the effects of estrogen antagonists on the gene expression profiles in MCF-7 cells. Furthermore, we analyzed the estrogen-responsive gene expression profiles in other ER-positive cancer cell lines derived from the breast, ovary, stomach and other tissues

\section{Materials and methods}

\section{Cell culture}

Human cancer cell lines derived from breast (MCF-7, MCF-7 c9 (Toi et al. 1993), T-47D and HBC-4 cells), ovary (OVCAR-5 and SK-OV-3 cells), stomach (MKN-28 and MKN-45 cells), brain (SF-539 cells), renal (ACHN and RXF-631 L cells), and human melanoma LOX-IMVI cells were maintained in RPMI 1640 medium (NISSUI Pharmaceutical, Tokyo, Japan) supplemented with $10 \%$ (MCF-7, MCF-7 c9 and T-47D cells) or 5\% (other cell lines) fetal bovine serum (FBS; Tissue Culture Biologicals, Turale, CA, USA). Human endometrium cancer Ishikawa-3H12 cells were cultured in Eagle's Minimum Essential Medium (EMEM; NISSUI Pharmaceutical) supplemented with $10 \%$ FBS. For treatment of the cells with estrogen or estrogen antagonists, each medium was replaced with phenol red-free RPMI 1640 medium (Sigma, St Louis, MO, USA) or phenol redfree EMEM (Sigma) containing FBS treated with dextran-coated charcoal (DCG-FBS). All the culture media contained $2 \mathrm{mM}$ L-glutamine (Sigma) and $40 \mu \mathrm{g} / \mathrm{ml}$ gentamicin (ScheringPlough, Osaka, Japan). All cells were incubated at $37^{\circ} \mathrm{C}$ in humidified air containing $5 \% \mathrm{CO}_{2}$.

\section{Large-scale cDNA microarray analysis}

Estrogen-responsive gene expression profiles were analyzed with a Human UniGEM v $2 \cdot 0$ microarray system (IncyteGenomics, Palo Alto, CA, USA) consisting of 9128 human cDNA clones covering 8502 unique gene/EST clusters. MCF-7 cells were cultured in the indicated phenol red-free medium with 10\% DCG-FBS for 5 days and treated with $10 \mathrm{nM} 17 \beta$-estradiol for $72 \mathrm{~h}$. From the cells, 
mRNA was prepared using a PolyATtract mRNA Isolation System III (Promega, Madison, WI, USA), following total mRNA isolation using an RNeasy kit (Qiagen, Tokyo, Japan), according to the manufacturer's instructions. Preparation of Cy3- or Cy5-labeled cDNA, hybridization, quantification of $\mathrm{Cy} 3$ and Cy5 signal intensities, and data analysis were carried out with IncyteGenomics microarray system.

\section{Production of custom-made cDNA microarrays}

To produce a prototype of the custom-made cDNA microarray, a total of 148 genes were selected from the gene set included in Human UniGEM v 2.0, according to the results obtained using this large-scale microarray system. The selected gene subset consisted of 138 genes which showed up- or down-regulation by estrogen, and 10 genes which showed no response to estrogen (for internal control) in the large-scale microarray analysis. For production of a second version of the custom-made cDNA microarray (InfoArray; InfoGenes Co. Ltd, Tsukuba, Japan), new genes were added, resulting in a total of 204 genes including 27 genes for internal control (details are described in Results). For each gene, PCR-amplified cDNA fragments were obtained and spotted in duplicate on each glass slide.

\section{Custom-made cDNA microarray hybridization}

For estrogen-responsive gene expression profiling, human cancer cells were grown in the indicated phenol red-free medium with 5 or $10 \%$ DCG-FBS for 5 days and treated with $10 \mathrm{nM} 17 \beta$-estradiol for $72 \mathrm{~h}$. For time-course analysis of estrogenresponsive gene expression profiles in $\mathrm{MCF}-7$ cells, the duration of $17 \beta$-estradiol treatment was 6,12 , 24 , and $72 \mathrm{~h}$. For the sample at $0 \mathrm{~h}$, the cells were also similarly cultured in estrogen-deprived medium but without any treatment. For analysis of the effects of estrogen antagonists, MCF-7 cells were treated with $10 \mathrm{nM} 17 \beta$-estradiol and either 4-hydroxytamoxifen (OHT, 1 or $5 \mu \mathrm{M}$ ) or ICI $182,780(1$ or $5 \mu \mathrm{M})$ for $72 \mathrm{~h}$, following estrogenstarved culture for 5 days. In every case, the cells used as references were treated with the same volume of ethanol. From the cells treated with those reagents, mRNA was isolated using PolyATtract system 1000 (Promega). The preparation of
Cy3- or Cy5-labeled cDNA and the hybridization procedure were performed according to a previous report (Arimura et al. 2000). Briefly, 2 to $4 \mu \mathrm{g}$ mRNA isolated from the cells treated with ethanol or the above-described ligands was reversetranscribed in the presence of Cy5-dUTP or Cy3-dUTP (Amersham Pharmacia Biotech) respectively, using SuperScript II RNaseH-Reverse Transcriptase (Gibco BRL) with 6-mer and 9-mer random primers. In the case of mRNA from the cells without any treatment $(0 \mathrm{~h}$ in time-course analysis), the same preparation of mRNA was divided and Cy3- or Cy5-labeled respectively. After the labeling reaction at $42{ }^{\circ} \mathrm{C}$ for $1 \mathrm{~h}$, cDNA-RNA hybrids were denatured under alkaline conditions for $1 \mathrm{~h}$. Unincorporated fluorescent nucleotides were removed by filtration through Microcon-30 columns (Millipore, Bedford, MA, USA). Cy3- and Cy5-labeled cDNA probes were mixed together, and after heat-denaturation the mixture was hybridized to a custom-made microarray slide in hybridization buffer $(2 \times \mathrm{SSC}$ plus $0 \cdot 2 \% \quad \mathrm{SDS})$ under a cover slip. Hybridization was carried out overnight at $65^{\circ} \mathrm{C}$ in a humidified hybridization chamber. The hybridized slides were washed three times with $2 \times \mathrm{SSC} / 0 \cdot 2 \% \mathrm{SDS}$ for $5 \mathrm{~min}$ at room temperature (RT), three times with $0 \cdot 2 \times \mathrm{SSC}$ / $0.2 \% \mathrm{SDS}$ for $5 \mathrm{~min}$ at $\mathrm{RT}$, three times with $0 \cdot 2 \times \mathrm{SSC} / 0 \cdot 2 \% \mathrm{SDS}$ for $5 \mathrm{~min}$ at $60{ }^{\circ} \mathrm{C}$, three times with $0 \cdot 2 \times \mathrm{SSC} / 0 \cdot 2 \% \mathrm{SDS}$ for $5 \mathrm{~min}$ at $\mathrm{RT}$, then rinsed four times with $0.2 \times \mathrm{SSC}$ at $\mathrm{RT}$. Finally, the remaining buffer on the slides was removed by centrifugation.

\section{Scanning and data analysis}

The fluorescent signals on the slides were scanned by ChipReader (Virtek, Ontario, Canada) and quantitative values for the signals were calculated using IPLab (Scanalytics, Fairfax, VA, USA) according to the manufacturer's instructions. Further data processing was carried out using Microsoft Excel software. For each spot, the ratio of $\mathrm{Cy} 3$ and $\mathrm{Cy} 5$ signal intensities (Cy3/Cy5) was calculated and $\log _{2}$-transformed. Each $\log _{2}(\mathrm{Cy} 3 /$ Cy5) value was normalized by subtracting the average of $\log _{2}(\mathrm{Cy} 3 / \mathrm{Cy} 5)$ values for internal control genes, and the duplicated $\log _{2}(\mathrm{Cy} 3 / \mathrm{Cy} 5)$ values for each gene were averaged. In the case of the analysis using InfoArray, the data for the spots with poor hybridization (signal areas of either Cy3 
or Cy5 were below 100) were removed from the data processing described above, to improve the correlation coefficients between duplicated sets of $\log _{2}(\mathrm{Cy} 3 / \mathrm{Cy} 5)$ values. In the case of the analysis using the prototype microarray, there was actually no need to cut off the data for improvement of the correlation coefficients (details are described in Results). Average-linkage hierarchical clustering was applied using the CLUSTER program and the results were displayed using the TREEVIEW program (both programs were developed by Eisen et al. 1998).

\section{Northern blot analysis}

For Northern blot analysis, MCF-7 cells were grown in estrogen-starved medium as in the case of microarray analysis and treated with ethanol or $10 \mathrm{nM} 17 \beta$-estradiol for $6,12,24$ or $72 \mathrm{~h}$. For the sample at $0 \mathrm{~h}$, the cells were also similarly cultured in the estrogen-deprived medium but without any treatment. Total RNA was prepared from each culture of the cells according to the method of Chomczynski and Sacchi (1987). For each sample, $20 \mu \mathrm{g}$ total RNA were used for Northern analysis. DNA fragments (420-570 bp) for hybridization probes were prepared by RT-PCR using total RNA from MCF-7 cells as a template and using an RNA PGR kit (AMV) ver. 2·1 (Takara Shuzo, Otsu, Japan). The sequences of the primers used in PCR amplification were as follows: 5'-GAG GCA ATG GCG ACG ATG G-3' and 5'-GTA GTC AAA GTC AGA GCA GTC-3' for $p S 2$ (Jakowlew et al. 1984); 5'-GTG GGG GGA AGA TGA AGG TC-3' and 5'-TTA CGC CAA GGG CAC ACG C-3' for insulin-like growth factor (IGF)-binding protein-4 (IGFBP4) (Kiefer et al. 1991b); 5'-TTC GAG AGC AAG TGG AAC CG-3' and 5'-AGC TCG TCG TGA ATG TGG TC-3' for KIAA1051 (Kikuno et al. 1999); 5'-AGG TGT GGA AGG CGT AAG TG-3' and 5'-TGG TAG CGG GTT AAG GCG AG-3' for retinoblastoma-binding protein 8 (Fusco et al. 1998); 5'-AAT GGG GGT TCT CAT GCT GG-3' and 5'-ATG TGG TTG ACT TTG AGG AGG-3' for c-myc promoterbinding protein 1 (Ray \& Miller 1991); 5'-ACG AAA AGA GCT ACG GGG AG-3' and 5'-TTG CTG CTG TCG AAG GTG TG-3' for insulin-like growth factor-binding protein-5 (IGFBP5) (Kiefer et al. 1991a); 5'-TGG AGG GAG GGA CGA CTG C-3' and 5'-AGA CAG TCG CGT GGG
GTG G-3' for solute carrier family 7 member 5 (Gaugitsch et al. 1992); 5'-GGA CAG AGG CTC GCG TTT G and 5'-CAT CAC GAT GGG AGT GGT A-3' for $\beta$-actin (Nakajima-Iijima et al. 1985). Twenty-five nanograms of cDNA fragments were labeled with $\left[\alpha-{ }^{32} \mathrm{P}\right] \mathrm{dCTP}$ using Megaprime DNA labeling systems (Amersham Pharmacia Biotech), and hybridization was carried out using ExpressHyb Hybridization solution (Clontech) according to the manufacturer's instructions.

\section{Results}

\section{Large-scale DNA microarray analysis for screening the estrogen-responsive genes}

First, we analyzed the estrogen-responsive gene expression profiles in human MCF-7 breast cancer cells using a Human UniGEM v 2.0 microarray system (IncyteGenomics) consisting of 9128 human cDNA clones covering 8502 unique gene/EST clusters. One of the purposes of our present research was to find the molecular markers which reflect the physiological status of ER-positive breast tumors supplied with a large amount of estrogen from themselves or from surrounding stromal cells for a long period. If such markers actually exist, these expression patterns should be quite valuable information for clinical application such as the diagnosis of estrogen- and anti-estrogenresponsiveness of mammary tumors. As a model cell line, we chose the MCF-7 cell line because it is ER $\alpha$-rich, highly responsive to estrogen and therefore has been extensively investigated as one of the standard models of ER-positive breast cancer. After MCF-7 cells were cultured in estrogen-starved medium for 5 days, the cells were treated with $10 \mathrm{nM} 17 \beta$-estradiol, which is considered to be a saturating estrogen-rich condition for the MCF-7 cells but physiologically relevant, and is also a possible condition present in the mammary glands. We set the duration time of estrogen treatment at $72 \mathrm{~h}$, with the aim of finding the genes exhibiting up- or down-regulation after such a long time of exposure to estrogen, which we think is one of the most important characteristics of a candidate for the markers we seek.

The ratios of differential expression of the genes between the MCF-7 cells with and without estrogen treatment are shown in Fig. 1A. Among a total of 9128 clones, the data for 1846 clones were cut off 
A

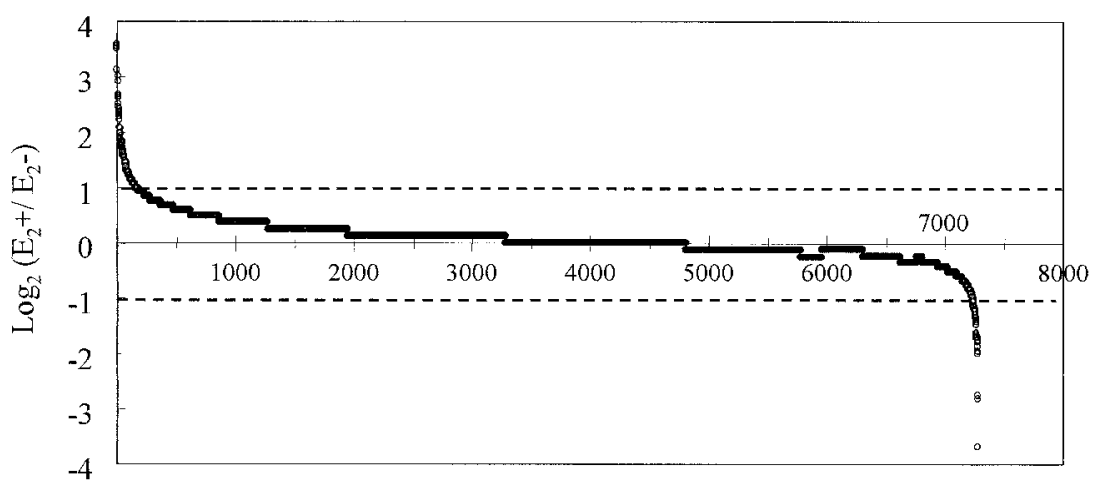

Gene No.

\section{B}

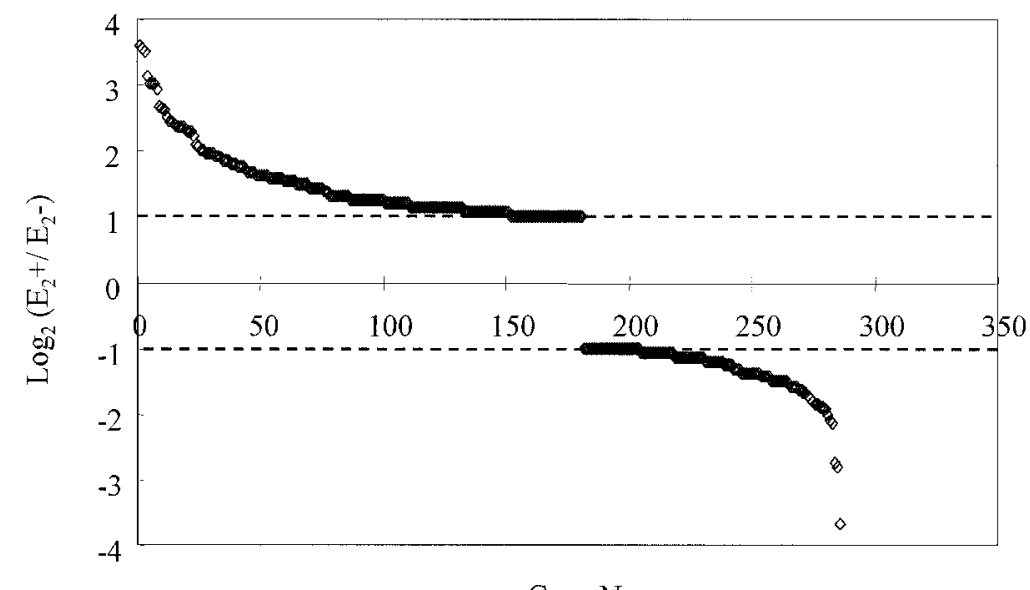

Figure 1 The results from gene expression profiling of MCF-7 cells treated with $\left(E_{2}+\right)$ or without $\left(E_{2}-\right) 10 \mathrm{nM} 17 \beta$-estradiol for $72 \mathrm{~h}$ using the large-scale microarray by IncyteGenomics. (A) Expression profiles of 7282 genes in MCF-7 cells. After filtrating the data for a total of 9128 genes loaded on the microarray according to the cut-off threshold defined by IncyteGenomics, the $\log _{2}$-transformed ratios of the expression levels of the remaining 7282 genes between the cells with or without estrogen $\left(E_{2}+/ E_{2}-\right)$ were plotted in order of the $E_{2}+/ E_{2}-$ ratios. The broken lines corresponding to $E_{2}+/ E_{2}-$ ratios equal to 2.0 or 0.5 are also indicated. (B) Expression profiles of 286 potentially estrogen-responsive genes in MCF-7 cells. From the 7282 genes plotted in panel $A, 181$ genes which showed $E_{2}+E_{2}-$ ratios equal to or $>2.0$ and 105 genes which showed $E_{2}+E_{2}-$ ratios equal to or $<0.5$ were selected and plotted in order of the $E_{2}+/ E_{2}-$ ratios. The broken lines corresponding to $E_{2}+E_{2}-$ ratios equal to 2.0 or 0.5 are also indicated. 
Table 1 Genes induced or repressed by estrogen treatment for 72 hours in MCF-7 breast cancer cells

\section{Gene name and category}

\section{Cancer-related genes}

Trefoil factor 1

Tumor protein D-52 like 1

Retinoblastoma-binding protein 8 (CtIP)

Tumor rejection antigen (gp96) 1

c-myc promoter-binding protein 1

\section{Growth-related genes}

Solute carrier family 7 , member 5

Insulin-like growth factor binding protein-4

Cyclin A1

TGFB inducible early growth response

Solute carrier family 12 , member 2

EGF-containing fibulin-like extracellular matrix protein

Insulin-like growth factor binding protein-5

\section{Transcription-related genes}

Activating transcription factor 3

Nuclear receptor interacting protein 1

Estrogen receptor $1(E R \alpha)$

\section{Others}

PDZK1

Stanniocalcin 2
Ratio of differential expression $\left(E_{2}+/ E_{2}-\text { or }-\left(E_{2}-/ E_{2}+\right)\right)^{a}$

\begin{tabular}{|c|c|c|c|c|}
\hline Incyte 1 & Incyte 2 & Custom & InfoArray & Accession no. \\
\hline $11 \cdot 7$ & 2.7 & $3 \cdot 2$ & $2 \cdot 4$ & X52003 \\
\hline $8 \cdot 1$ & $5 \cdot 0$ & $2 \cdot 7$ & $3 \cdot 7$ & U44427 \\
\hline 3.9 & $2 \cdot 2$ & $5 \cdot 1$ & $2 \cdot 3$ & NM_002894 \\
\hline $3 \cdot 3$ & $2 \cdot 6$ & 1.8 & $2 \cdot 8$ & X15187 \\
\hline-2.6 & -4.5 & $-6 \cdot 0$ & -3.5 & Al338641 \\
\hline
\end{tabular}

\section{$5 \cdot 5$}

4.0

M80244

$5 \cdot 3$
3.5

3.4

3.4

$-4 \cdot 3$

$-6 \cdot 7$

$-7 \cdot 0$

$8 \cdot 3$
$3 \cdot 1$
$2 \cdot 1$
$2 \cdot 5$
$-4 \cdot 8$
$-2 \cdot 4$
$-2 \cdot 8$

$8 \cdot 0$
3.4

$2 \cdot 8$

$2 \cdot 4$

$2 \cdot 5$

$2 \cdot 3$

$-4 \cdot 8$

$-2 \cdot 1$

$-4 \cdot 1 \quad-1.8$

$-3.6 \quad-2 \cdot 1$

M62403

U66838

AF050110

NM 001046

บ03877

AW157548

$\begin{array}{rrrrr}4.9 & 4.5 & 2.4 & 4.3 & \text { N39944 } \\ 3.0 & 2.6 & 3.6 & 2.4 & \text { X84373 } \\ -3.0 & -1.5 & -1.9 & -1.9 & \text { X03635 }\end{array}$

\footnotetext{
a'Ratio of differential expression' means the ratio of expression levels of each gene in MCF-7 cells treated with $\left(E_{2}+\right)$ and without $\left(E_{2}-\right) 17 \beta$-estradiol. For $E_{2}$-upregulated or $E_{2}$-downregulated genes, the values are shown as the ratios $E_{2}+/ E_{2}-$ or $-\left(E_{2}-/ E_{2}+\right)$ respectively. These data were obtained using the microarray of IncyteGenomics (Incyte 1 and Incyte 2, from two-times hybridization), prototype customized microarray (custom) or InfoArray. TGFB, transforming growth factor $\beta$; EGF, epidermal growth factor.
}

due to low signal intensities as defined by the manufacturer (IncyteGenomics). Among the remaining 7282 clones, 181 genes showed differential expression ratios equal to or more than $2 \cdot 0$, and 105 genes showed differential expression ratios equal to or less than 0.5 (shown in Fig. 1B); the remaining $96 \%$ of the genes revealed no significant differences in their expression levels.

In the total of 286 genes which proved to be potentially estrogen-responsive genes by this analysis, there were some genes which had previously been reported to be induced by estrogen, such as pS2 (trefoil factor 1, Brown et al. 1984), PDZK1 (Ghosh et al. 2000), IGFBP4 (Qin et al. 1999) and nuclear receptor interacting protein 1 (Thenot et al. 1999), indicating the reliability of this analysis. These genes are listed in Table 1 with the differential expression ratios in response to $17 \beta$-estradiol (shown as 'Incyte $1^{\prime}$ ). Other potentially estrogen-responsive genes which we considered to be related to estrogen-dependent growth and/or tumor progression were selected from the 286 genes referring to the background information of those genes, and are also listed in Table 1.

The estrogen-responsive gene expression profiling of MCF-7 cells by the microarray of IncyteGenomics was carried out once more, using mRNA isolated from the cells of another culture. The correlation coefficient between the expression ratios of the 286 genes that resulted from two-times microarray analysis was $0 \cdot 819$, and concerning the genes listed in Table 1, not identical but similar estrogen-responsive expression patterns were obtained by both analyses (shown as 'Incyte 1' and 'Incyte 2').

\section{Time course of estrogen response}

From the 286 potentially estrogen-responsive genes mentioned above, a total of 138 genes were selected for production of a prototype of the custom-made microarray, removing the genes which showed 
relatively low ratios of estrogen-responsive expression (near or equal to $2 \cdot 0$ or $-2 \cdot 0$ ) and were inferred to have little relation to the nature of breast cancer according to the background information on the genes.

Using this customized microarray prototype, we analyzed the time course of estrogen response of the genes in MCF-7 cells. The estrogen-starved MCF-7 cells were treated with ethanol $\left(\mathrm{E}_{2}-\right)$ or $10 \mathrm{nM} 17 \beta$-estradiol $\left(\mathrm{E}_{2}+\right)$ for $6,12,24$ or $72 \mathrm{~h}$ and mRNA isolated from each culture of the cells was used for the microarray analysis. The mRNA was also isolated from the estrogen-starved cells but without any treatment (shown as $0 \mathrm{~h}$ ). On the custom microarray, cDNA fragments for each gene were spotted in two blocks, yielding a pair of data sets of expression ratios from one hybridization. The correlation coefficients between pairs of gene expression ratios from one hybridization were $0.603,0 \cdot 835,0.949,0.833$ and 0.978 at $0,6,12,24$ and $72 \mathrm{~h}$ of estrogen treatment respectively, without filtering the data. The relatively lower correlation coefficient at $0 \mathrm{~h}$ was considered to be due to random scattering of the $\mathrm{Cy} 3 / \mathrm{Cy} 5$ ratios that resulted from technical variation in fluorescent labeling and/or hybridization. Filtration of the data of ratios according to the criterion used in the case of InfoArray analysis (see Materials and methods) resulted in no or little increase in these correlation coefficients (not shown). Therefore, further data analysis was performed without filtration.

The expression ratios of several genes at the final time point $(72 \mathrm{~h})$ are shown in Table 1 (as 'Custom'). At least for the genes listed in Table 1, similar results to those from large-scale microarray analysis were obtained. The estrogen-responsive expression patterns of a total of 148 genes were analyzed by hierarchical clustering and represented as a pseudo-color visualization matrix (Fig. 2). As shown in Fig. 2, hierarchical clustering clearly highlighted the gene clusters of estrogen-induced and estrogen-repressed genes, and made it possible to subdivide the cluster of estrogen-induced genes into two subgroups; one group contained the genes which showed expression ratios above 2.0 after $12 \mathrm{~h}$ of estrogen treatment (early-responsive estrogen-induced genes, group A in Fig. 2) and the other group contained the genes which showed significant expression after $24 \mathrm{~h}$ or, in most cases, $72 \mathrm{~h}$ of estrogen treatment (late-responsive estrogen-induced genes, group B in Fig. 2). On the other hand, the cluster of estrogen-repressed genes (Group C in Fig. 2) did not show any apparent subgroups.

Figure 3 shows the time course of estrogenresponsive expression of the several genes selected from groups A, B and C in Fig. 2. As expected, $p S 2$ (trefoil factor), IGFBP4 and cathepsin D, which were reported to be the target genes of ER $\alpha$ (Brown et al. 1984, Qin et al. 1999 and Augereau et al. 1994 respectively), were found in the group of early-responsive estrogen-induced genes (Fig. 2A). Solute carrier family 7 member 5 (SCF7, also named E16) was reported to be induced by estrogen (Soulez \& Parker 2001) and was also found in the same group as $p S 2$ etc. in our analysis, but the expression pattern was different from those of other genes in that the expression level increased persistently up to $72 \mathrm{~h}$. Insulin-like growth factorbinding protein-5 (IGFBPS), which was reported to be down-regulated by estrogen (Huynh et al. 1996), was found in the group of estrogen-repressed genes (Fig. 2C). These observations indicate the reliability of this customized microarray for analyzing the estrogen-responsive genes, and the usefulness of the time-course study by this microarray for characterization of the estrogen-regulated genes.

\section{Northern blot analysis of representative estrogen-induced or -repressed genes}

To confirm the estrogen-responsive gene expression patterns obtained by custom microarray analysis, we selected several genes from those shown in Fig. 3 and carried out Northern blot analysis concerning those selected genes. As shown in Fig. 4, IGFBP4, pS2, KIAA1051 and SCF7 in the early-responsive estrogen-induced gene group showed similar expression patterns to those obtained by microarray analysis. All four genes were rapidly and significantly induced by the addition of $17 \beta$-estradiol (20-fold, 2-fold, 2-fold and 3 -fold $\mathrm{E}_{2}+/ \mathrm{E}_{2}-$ expression ratios at $6 \mathrm{~h}$ in IGFBP4, pS2, KIAA1051 and SCF7 respectively). In the case of SCF7, the mRNA level was increased continuously up to $72 \mathrm{~h}$, resulting in 6 -fold $(6 \cdot 1 \mathrm{~kb}$ transcript) and 9-fold ( $4 \cdot 1 \mathrm{~kb}$ transcript) $\mathrm{E}_{2}+/ \mathrm{E}_{2}-$ ratios at $72 \mathrm{~h}$, which is consistent with the induction pattern depicted in Fig. 3. In contrast, the mRNA of retinoblastoma-binding protein 8 (RbBP8), which was found in the late-responsive estrogen-induced gene group, was detected only 


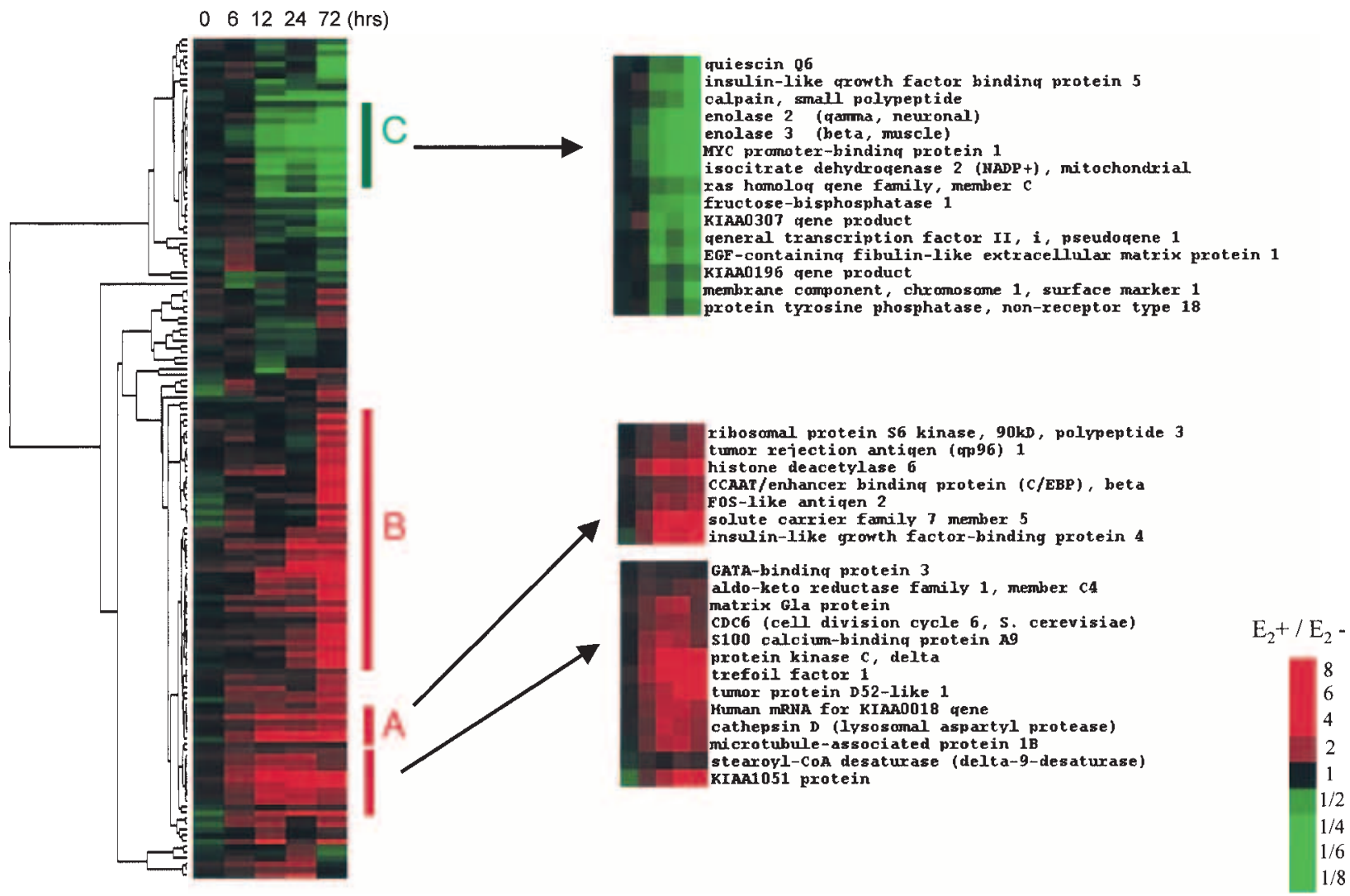

Figure 2 Gene expression patterns in MCF-7 cells at different times after estrogen stimulation. MCF-7 cells incubated in estrogen-deprived medium were treated with $10 \mathrm{nM} 17 \beta$-estradiol $\left(E_{2}+\right)$ or ethanol $\left(E_{2}-\right)$ for $6,12,24$ and $72 \mathrm{~h}$; mRNA was isolated from each cell culture and from the cells without any treatment (shown as $0 \mathrm{~h}$ ), and was then used for prototype customized cDNA microarray analysis as described in Materials and methods. The expression patterns of 148 genes were analyzed by hierarchical clustering and were represented as a pseudo-color visualization matrix using CLUSTER and TREEVIEW (Eisen et al. 1998). Gene clusters denoted by the bars and letters $\mathrm{A}, \mathrm{B}$ and $\mathrm{C}$ are the groups containing early-responsive estrogen-induced genes, late-responsive estrogeninduced genes and estrogen-repressed genes respectively. The gene groups A and C are zoomed and the expression patterns with gene names are shown on the right. The color scale used to represent the expression ratios is shown on the lower right.

at $72 \mathrm{~h}$ after the estrogen treatment. At $72 \mathrm{~h}$, RbBP8 mRNA appeared both under $\mathrm{E}_{2}+$ and $\mathrm{E}_{2}-$ conditions, but the $\mathrm{E}_{2}+/ \mathrm{E}_{2}-$ ratio of the expression levels was $3 \cdot 8$, which is consistent with the data obtained by microarray analysis (Fig. 3B). IGFBP5 and c-myc promoter-binding protein 1 (MYC-BP1) in the estrogen-repressed gene group showed repression by estrogen treatment, and at $72 \mathrm{~h}$, 7-fold (IGFBP5) and 3-fold (MYG-BP1) reductions between $\mathrm{E}_{2}-$ and $\mathrm{E}_{2}+$ conditions were observed, similar to the data shown in Fig. 3C. The similar results obtained by microarray and Northern analysis emphasize the usefulness and reliability of the customized microarray system for analyzing the expression profiles of the estrogen-regulated genes.

\section{Estrogen-responsive gene expression profiles in the presence of estrogen antagonists}

Next, we developed a second version of the custom-made cDNA microarray, with a larger number of genes loaded on it. On this microarray (named InfoArray), new genes were added resulting in a total of 204 genes, including 27 genes for internal control. The newly added gene group included the genes found as estrogen-responsive or not estrogen-responsive (as internal control genes) 
A
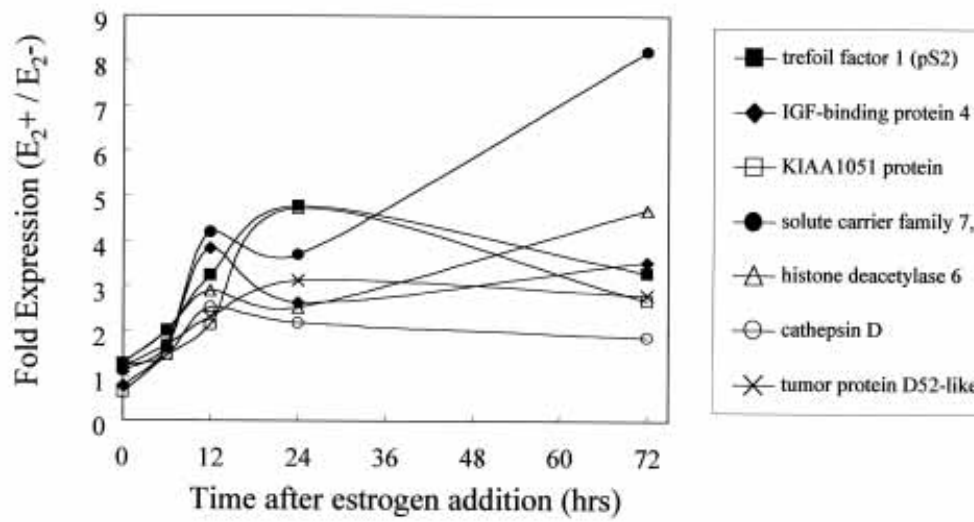

- solute carrier family 7 , member 5

$\triangle$ bistone deacetylase 6

- cathepsin D

$\times$ tumor protein DS2-like 1

B

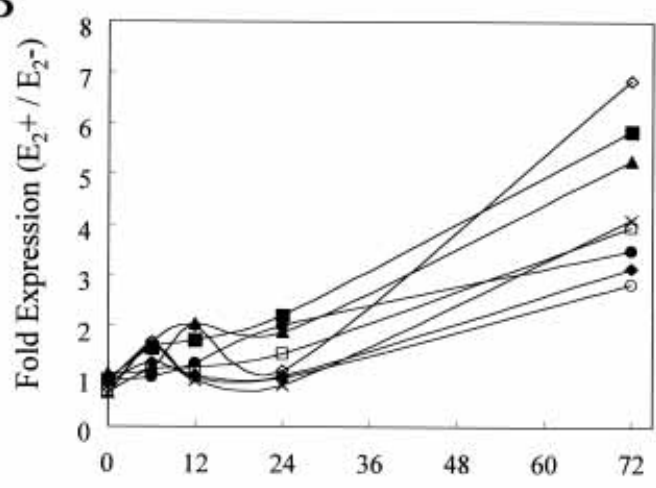

- retinoblastoma-binding protein 8

- asparagine synthetase

$\diamond$ EST (N35555)

- ESTs, Highly similar to phosphoserine aminotransferase (AA.587912)

$-\operatorname{cyclin} \mathrm{Al}$

$*$ down-regulated in adenoma

pituitary tumor-transforming 1

$\square$ tryptophanyl-tRNA synthetase

Time after estrogen addition (hrs)

$\mathrm{C}$

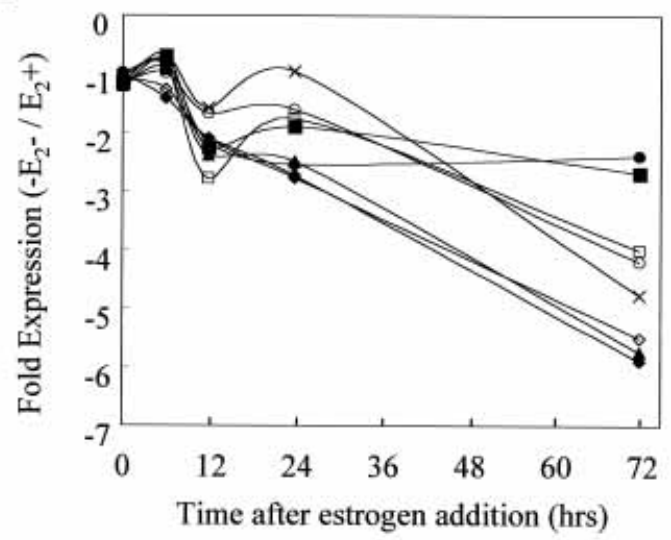

Figure 3 Expression profiles of several genes in MCF-7 cells at different times after estrogen stimulation analyzed by prototype customized microarrays. From the gene groups A, B and C in Fig. 2, several genes were selected and the time courses of the ratios of expression levels between the cells treated with $17 \beta$-estradiol $\left(E_{2}+\right)$ and with ethanol $\left(E_{2}-\right)$ were plotted. Panels $A, B$ and $C$ show the expression patterns of early-responsive estrogen-induced genes, late-responsive estrogen-induced genes and estrogen-repressed genes respectively. EGF, epidermal growth factor. 


\section{Estradiol Treatment}

$\mathrm{pS} 2$

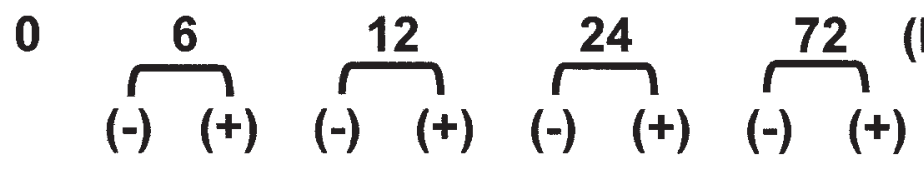

(h)

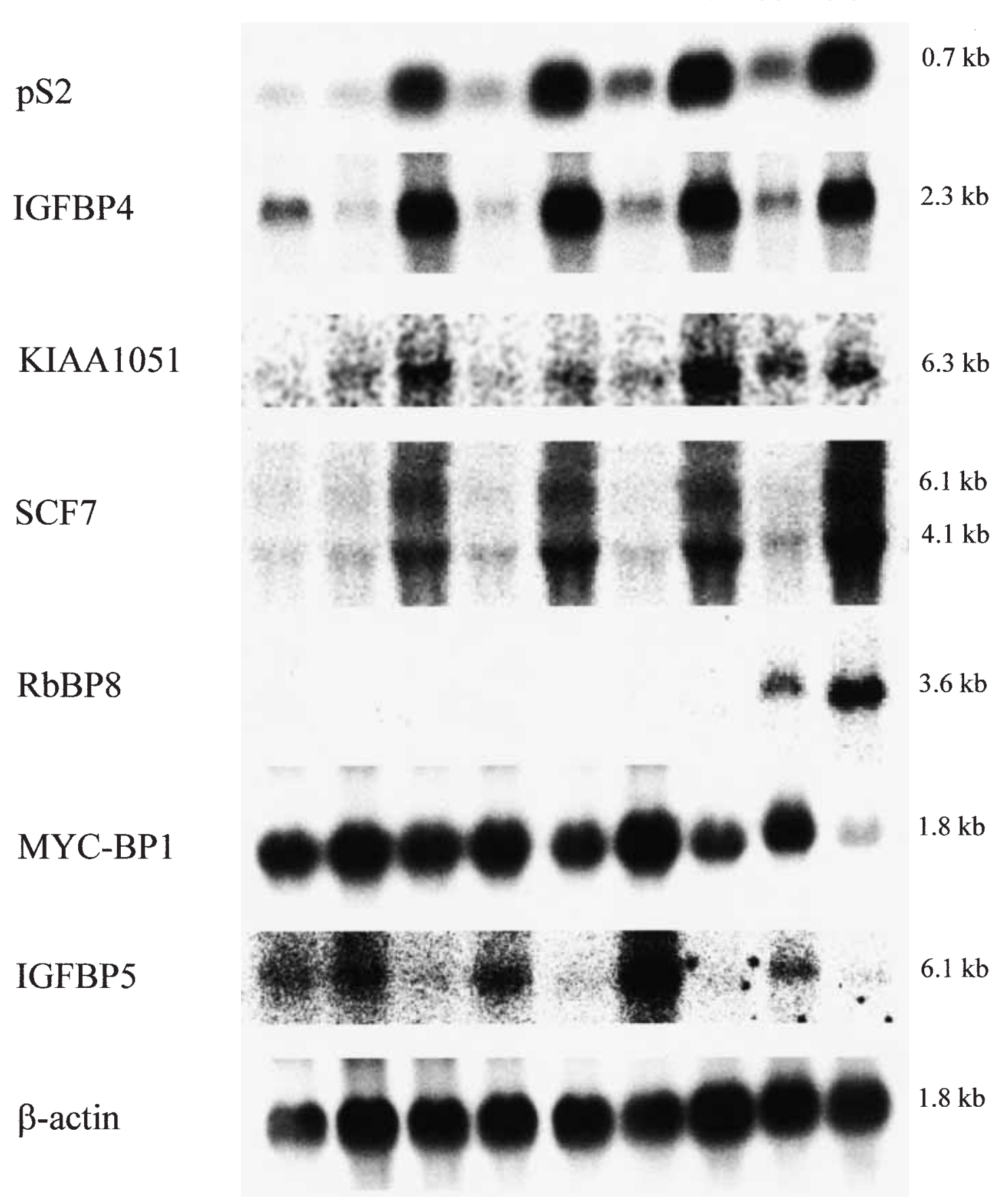


by large-scale microarray analysis but not loaded on the prototype custom microarray. The group also included the genes for which there was no experimental evidence to consider them estrogenresponsive but whose expression levels would be critical for the physiology of breast cancer, such as aromatase and estrogen sulfatase. The cDNA fragments for each gene were spotted in duplicate as in the case of the prototype customized microarray. Using this microarray (InfoArray), we analyzed the effects of anti-estrogens, that is, OHT and ICI 182,780, on the estrogen-responsive gene expression profiles of MCF-7 cells. One of the purposes of this analysis was to subdivide the estrogen-responsive genes loaded on InfoArray into those genes regulated through the pathway involving ER $\alpha$ and those genes regulated independently of ER $\alpha$. MCF-7 cells cultured in estrogendeprived medium were treated with ethanol $\left(\mathrm{E}_{2}-\right)$, $10 \mathrm{nM} 17 \beta$-estradiol $\left(\mathrm{E}_{2}+\right)$ alone, $10 \mathrm{nM} \mathrm{E}_{2}$ and $1 \mu \mathrm{M}$ or $5 \mu \mathrm{M} \mathrm{OHT}$, or $10 \mathrm{nM} \mathrm{E}_{2}$ and $1 \mu \mathrm{M}$ or $5 \mu \mathrm{M}$ ICI 182,780 for $72 \mathrm{~h}$, then mRNA was isolated from each cell culture. The mRNA from the $\mathrm{E}_{2}-$ cells was used for Cy5-labeling and the mRNA from the cells treated with abovementioned ligands was used for Cy3-labeling, and the fluorescent-labeled cDNA probes were hybridized to InfoArray.

Filtration of the data for the $\mathrm{E}_{2}+/ \mathrm{E}_{2}-$, $\left(\mathrm{E}_{2}+\mathrm{OHT}\right) / \mathrm{E}_{2}-$ and $\left(\mathrm{E}_{2}+\mathrm{ICI}\right) / \mathrm{E}_{2}-$ ratios was performed using our own criteria (described in Materials and methods), cutting off the data for the spots with poor hybridization (signal areas for either Cy3 or Cy5 below 100). By filtrating the data, all correlation coefficients between duplicated sets of the ratios obtained from a total of five microarray experiments increased significantly, resulting in the values ranging from 0.876 to 0.948 .

The expression ratios of several genes in MCF-7 cells stimulated by $17 \beta$-estradiol only are shown in Table 1 (as 'InfoArray'). At least for the genes listed in Table 1, we obtained similar results to those from large-scale microarray analysis and the prototype custom microarray analysis.

From the total of 204 genes on InfoArray, 168 genes for which there were remaining data in at least three culture conditions were selected and those expression patterns were analyzed by hierarchical clustering (Fig. 5). In the presence of $1 \mu \mathrm{M}$ or $5 \mu \mathrm{M}$ ICI 182,780 , almost all the estrogen-responsive genes showed no regulation by estrogen. Some genes (cluster d in Fig. 5) showed lower expression levels in the presence of $17 \beta$-estradiol and ICI 182,780 than under $\mathrm{E}_{2}-$ conditions, which was possibly due to the low level of induction of those genes by traces of estrogen under $\mathrm{E}_{2}-$ conditions and suppression of the induction by ICI 182,780. Group d contains well-known estrogen-responsive genes such as trefoil factor $(p S 2)$ and IGFBP4, suggesting that these genes may have a lower threshold of estrogen concentration for induction than other estrogenregulated genes. The estrogen-repressed genes in group $\mathrm{f}$ showed higher expression levels in the presence of ICI 182,780 than under $\mathrm{E}_{2}-$ conditions, which is possibly due to the low level of repression of those genes by traces of estrogen under $\mathrm{E}_{2}-$ conditions and suppression of this $\mathrm{E}_{2}-$ repression by ICI 182,780. Group f contains IGFBP5, which has been reported to be downregulated by estrogen and up-regulated by ICI 182,780 (Huynh et al. 1996). Because ICI 182,780 is recognized as a pure anti-estrogen and is considered to repress all estrogen-responsive promoter contexts (Hall et al. 2001), these observations suggest that almost all the estrogen-responsive genes are regulated by estrogen through ERdependent mechanisms or pathways.

In the presence of $5 \mu \mathrm{M}$ OHT, the regulation of many genes (group c, d, and f in Fig. 5) by estrogen was completely abolished by OHT, similar to the case of ICI 182,780 treatment. But several genes showed residual regulation by estrogen even in the presence of a high concentration of OHT. For

Figure 4 Northern blot analysis of several genes selected from the genes shown in Fig. 3. Estrogen-starved MCF-7 cells were treated with $17 \beta$-estradiol or ethanol for $6,12,24$, and $72 \mathrm{~h}$ and total RNA was isolated from each culture of the cells and from the cells without any treatment (shown as $0 \mathrm{~h}$ ). From each sample, $20 \mu \mathrm{g}$ total RNA were taken for Northern blot analysis, and cDNA fragments of the genes listed on the left were used as probes. The sizes of the transcripts are shown on the right. Abbreviations are as follows: IGFBP4, insulin-like growth factor-binding protein-4; SCF7, solute carrier family 7 member 5; RbBP8, retinoblastoma-binding protein 8; MYC-BP1, c-myc promoterbinding protein 1; IGFBP5, insulin-like growth factor-binding protein-5. Northern blot analysis of $\beta$-actin was also carried out as an internal control. 


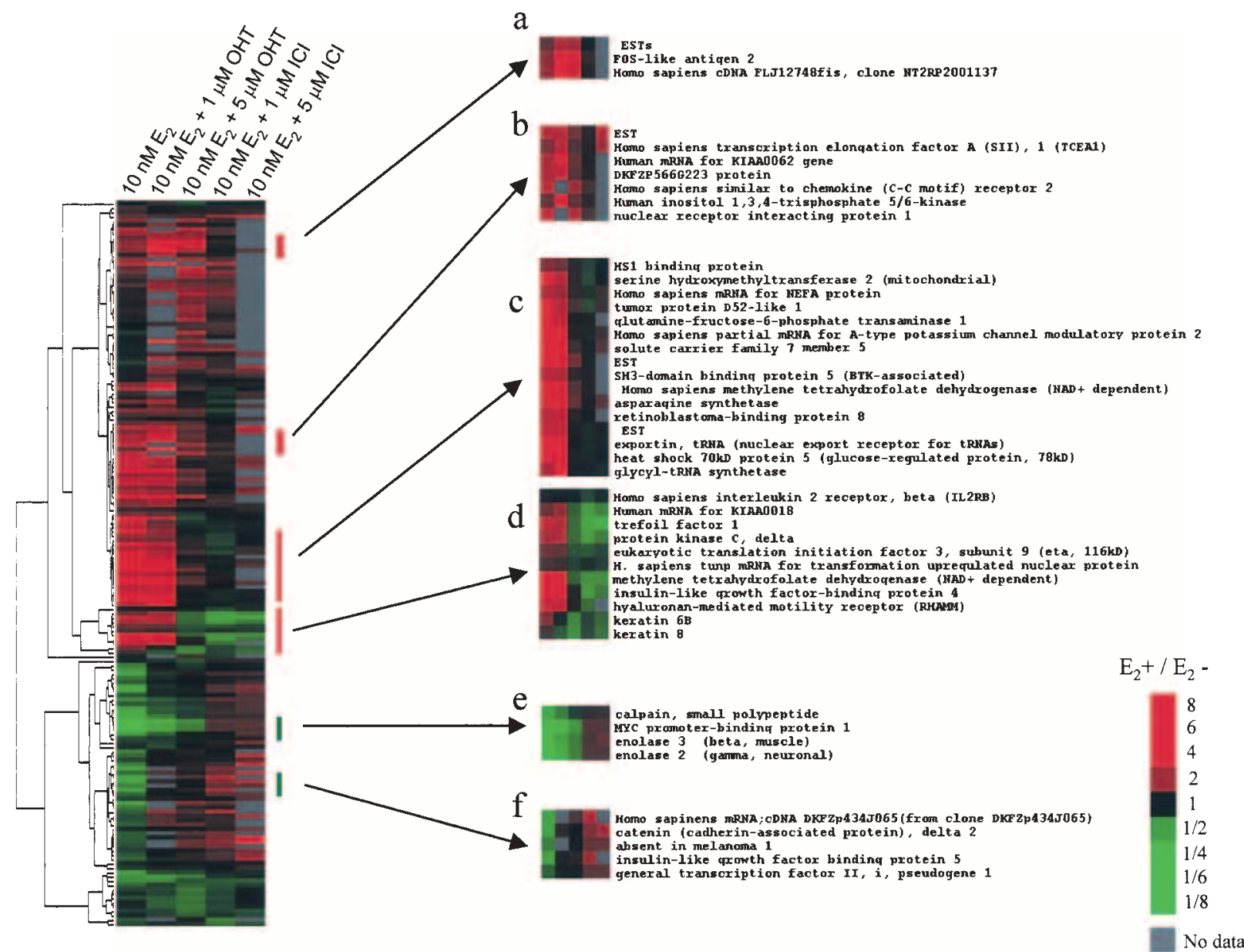

Figure 5 Gene expression patterns in MCF-7 cells in the presence of $10 \mathrm{nM} 17 \beta$-estradiol $\left(\mathrm{E}_{2}\right)$, or $10 \mathrm{nM} \mathrm{E}_{2}$ and either 4-hydroxytamoxifen (OHT) or ICI 182,780 (ICl). MCF-7 cells cultured in estrogen-deprived medium were treated with ethanol $\left(E_{2}-\right), 10 \mathrm{nM} 17 \beta$-estradiol $\left(E_{2}+\right)$ alone or $10 \mathrm{nM} \mathrm{E} E_{2}$ together with either OHT $(1 \mu \mathrm{M}$ or $5 \mu \mathrm{M})$ or ICI $182,780(1 \mu \mathrm{M}$ or $5 \mu \mathrm{M})$ for $72 \mathrm{~h}$, then mRNA was isolated from each cell culture. The mRNA from the $\mathrm{E}_{2}-$ cells was used for Cy5-labeling and mRNA from the cells treated with the ligands was used for Cy3-labeling, and gene-expression profiles were analyzed using InfoArray. After filtrating the data of expression ratios according to the criterion described in Materials and methods, 168 genes for which there were remaining data in at least three culture conditions were selected from a total of 204 genes loaded on InfoArray, and analyzed by hierarchical clustering. The results are represented as a pseudo-color visualization matrix as in Fig. 2. The characters of gene clusters denoted by the bars and letters a to f are as follows: a, group containing the genes whose differential expression ratios exceeded 2.0 only in the presence of both estrogen and $\mathrm{OHT} ; \mathrm{b}$, group containing the genes which were induced by estrogen both in the presence and absence of $\mathrm{OHT}$; c, group including the genes which were estrogen-induced and where the presence of $\mathrm{ICI} 182,780$ or OHT completely abolished the regulation by estrogen; $d$, group containing the genes which showed similar expression patterns as group c, but are different in that the presence of $\mathrm{ICl} 182,780$ resulted in apparent down-regulation; e, group containing the genes which were repressed by estrogen both in the presence and absence of OHT; $f$, group including the genes which were estrogen-repressed and where the presence of $\mathrm{OHT}$ or ICI 182,780 completely abolished the regulation. All the gene groups are zoomed and the expression patterns with gene names are shown on the right. The color scale used to represent the expression ratios is shown on the lower right. The gray color means that there are no reliable data after filtrating due to poor hybridization.

example, nuclear receptor interacting protein 1 in group $b$, which showed $2 \cdot 4$-fold induction by estrogen, showed $2 \cdot 2$-fold induction in the presence of $5 \mu \mathrm{M}$ OHT. c-myc promoter-binding protein 1 in group e, which showed $3 \cdot 5$-fold reduction by estrogen, was also reduced by $1 \cdot 9$-fold in the 
presence of estrogen and $5 \mu \mathrm{M}$ OHT. In group a, one gene (FOS-like antigen 2) and one clone (cDNA FLJ12748 fis, clone NT2RP2001137) showed expression ratios above $2 \cdot 0$ only in the presence of OHT. The significance of the expression patterns of these gene/clones in relation to breast cancer is unknown, but there is a possibility that induction of these genes reflects the activation of other mechanisms of the effects of tamoxifen on breast cancer apart from inhibition of $\mathrm{ER} \alpha$, such as apoptosis (Mandlekar \& Kong 2001).

In the presence of $1 \mu \mathrm{M}$ OHT, most of the estrogen-induced genes (group b, c and d in Fig. 5) showed above $2 \cdot 0$-fold induction by estrogen, suggesting that this concentration of OHT is not sufficient for complete inhibition of $\mathrm{ER} \alpha$ function, which was quite different from the effects of the same concentration of ICI 182,780.

These observations on the effects of OHT suggest that there is a small number of genes whose regulation by estrogen is not completely abolished by OHT, but that most of the genes lost induction or repression by estrogen, which is consistent with the fact that tamoxifen inhibits the proliferation of at least a part of ER-positive breast tumors.

\section{Estrogen-responsive gene expression profiles in other cancer cell lines}

Finally, we analyzed the estrogen-responsive gene expression profiles of twelve cancer cell lines other than MCF-7 cells using InfoArray. MCF-7 c9 cells were cloned and established as a tamoxifenresistant sub-line of MCF-7 cells by Toi et al. (1993). Other cell lines were derived from breast, ovary, endometrium, stomach, brain, renal or melanoma cells (details are in Materials and methods). ER $\alpha$ mRNA was detected by RT-PGR in all the cell lines, although most of the cell lines other than MCF-7 cells showed low level expression of $\mathrm{ER} \alpha$ (data not shown). Each cell line was cultured in estrogen-deprived medium and treated with ethanol $\left(\mathrm{E}_{2}-\right)$ or $10 \mathrm{nM} 17 \beta$-estradiol $\left(\mathrm{E}_{2}+\right)$ for $72 \mathrm{~h}$. Gene expression patterns of these cell lines were obtained using InfoArray. After cutting off the data for the spots with poor hybridization according to the criterion as described in a previous section and in Materials and methods, correlation coefficients between duplicated sets of expression ratios obtained by hybridization increased significantly (data not shown). From a total of 204 genes loaded on InfoArray, 179 genes for which there were remaining data in at least seven cell lines were selected and analyzed by hierarchical clustering, including the gene expression profiles of MCF-7 cells treated with estrogen (the same data as shown in Fig. 5).

As shown in Fig. 6, several characteristic genes or gene clusters were observed although most of the genes exhibited regulation by estrogen only in MCF-7 cells. For example, all the genes in group a showed above $2 \cdot 5$-fold induction by estrogen in MCF-7 cells but not in other cells (and not in MCF-7 c9 cells). The gene denoted as 'mal, T-cell differentiation protein' in group b showed $2 \cdot 8$-fold induction by estrogen only in stomach MKN-28 cells. The genes in group c were induced by $2 \cdot 0-$ or above $2 \cdot 0$-fold after estrogen stimulation in both MCF-7 and T-47D breast cancer cells. The genes in group $\mathrm{d}$ showed higher induction ratios in MCF-7 c9 than in MCF-7 cells; for example, KIAA0018 was induced 1.6-fold in MCF-7 cells but $9 \cdot 8$-fold in MCF-7 c9 cells. Ribosomal protein L35 in group e was repressed by estrogen in several cell lines; $2 \cdot 0-, 2 \cdot 4-, 2 \cdot 8-$ and $2 \cdot 0$-fold reduction in MCF-7 c9, SK-OV-3, MKN-28 and MKN-45 respectively.

In contrast with MCF-7 cells, there was too small a number of estrogen-regulated genes in other cell lines to be highlighted as gene groups by hierarchical clustering, and therefore these gene expression patterns were apparently far from reflecting the effects of estrogen on each organ from which each cell line was derived. But in the pseudo-color visualized matrix shown in Fig. 6, there are a few genes showing expression ratios of $2 \cdot 0$-fold or above $2 \cdot 0$-fold in each cell line, suggesting that these expression profiles imply the cell-type specific response to estrogen treatment.

\section{Discussion}

We report here on our on-going cDNA microarray analysis to specify estrogen-responsive genes, some of which would be critical for the development of breast cancer and also for the prediction of individual responses to anti-hormone therapy. Our first goal is the integrated and precise selection of patients for anti-hormone therapy, which is 


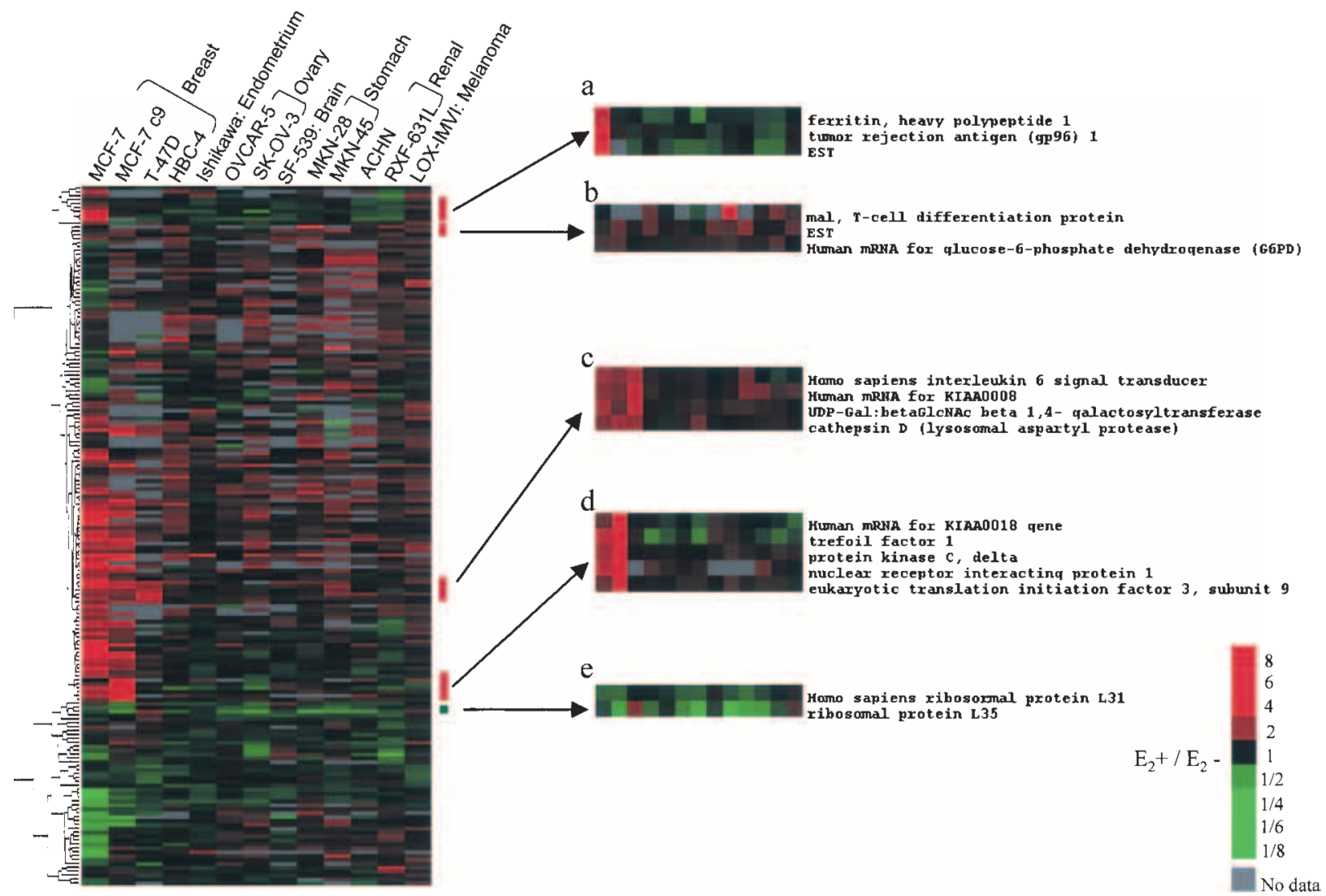

Figure 6 Gene expression patterns in MCF-7 and twelve other cancer cell lines in the presence of $10 \mathrm{nM}$ $17 \beta$-estradiol $\left(E_{2}\right)$. The cancer cell lines cultured in estrogen-deprived medium were treated with ethanol $\left(E_{2}-\right)$ or $10 \mathrm{nM} 17 \beta$-estradiol $\left(\mathrm{E}_{2}+\right)$ for $72 \mathrm{~h}$ and mRNA was isolated from each culture of the cells. The mRNA from the $\mathrm{E}_{2}-$ and $E_{2}+$ cells was used for Cy5- and Cy3-labeling respectively, and gene-expression profiles were analyzed using InfoArray. After filtrating the data of expression ratios according to the criterion described in Materials and methods, 179 genes for which there were remaining data in at least seven cell lines were selected from a total of 204 genes loaded on InfoArray, and analyzed by hierarchical clustering. The results are represented as a pseudo-color visualization matrix as in Fig. 2. The characters of gene clusters denoted by the bars and letters a to e are as follows: a, group containing the genes estrogen-induced only in MCF-7 cells (not induced by estrogen in MCF-7 c9 cells); b, group containing one gene which was induced by estrogen only in MKN-28 stomach cancer cells; c, group including the genes induced by estrogen both in MCF-7 and T-47D breast cancer cells; $d$, group containing the genes highly estrogen-induced in MCF-7 c9 cells; e, group containing one gene repressed by estrogen in several cancer cell lines. All the gene groups are zoomed and the expression patterns with gene names are shown on the right. The color scale used to represent the expression ratios is shown on the lower right. The gray color means that there are no reliable data after filtrating due to poor hybridization.

urgently needed for the clinical treatment of breast cancer.

For all cDNA microarray analyses except time-course analysis, MCF-7 cells (and also other cancer cells) were treated with $10 \mathrm{nM} 17 \beta$-estradiol for $72 \mathrm{~h}$. As described in Results, we decided on an estrogen exposure duration of $72 \mathrm{~h}$ because we considered that stable or persistent estrogenresponsive expression of the genes is one of the most important criteria for the selection of candidates for prognostic and/or diagnostic markers for breast tumors supplied with estrogen for a long time in patients. Conversion from ER-positive to ER-negative status in breast cancer in vivo along with loss of sensitivity to anti-hormone therapy is one of the most important clinical problems, and anti-hormone therapy will be most effective in those tumors in the status saturated with estrogen and heavily estrogen-dependent for growth. According to this speculation, we decided 
to perform gene expression profiling of ER-rich breast cancer MCF-7 cells stimulated with a saturating but physiologically relevant concentration $(10 \mathrm{nM})$ of estrogen for $72 \mathrm{~h}$.

First, screening of the estrogen-responsive genes in MCF-7 cells using a large-scale cDNA microarray revealed that a limited number of genes were sufficient for profiling estrogen responsiveness. The fact that $96 \%$ of the genes loaded on the microarray of IncyteGenomics exhibited no or little regulation by estrogen even in ER-rich MCF-7 cells prompted us to develop a custom-made cDNA microarray system containing only a narroweddown estrogen-responsive gene subset.

The 138 estrogen-responsive genes/ESTs selected contained the genes previously reported to be early-responsive estrogen-induced genes such as pS2 (trefoil factor) and IGFBP4 (Qin et al. 1999). From this fact we inferred that in the total of 138 genes there would be some unidentified earlyresponsive genes closely related to the physiology of breast cancer. Therefore, we analyzed the time course of estrogen-responsive gene expression profiles in MCF-7 cells using the custom-made microarray and the obtained results were confirmed by Northern blot analysis.

As expected, we identified KIAA1051, which is one of the functionally unidentified genes, as a novel early-responsive gene. But clarification of the function of the gene and the significance of estrogen-responsiveness in relation to breast cancer depend on further investigation. Solute carrier family 7 member 5 (SCF7), another identified early-responsive gene, was also reported to be induced by estrogen in ZR75-1 breast cancer cells (Soulez \& Parker 2001), suggesting that the regulation mechanism of SCF7 by estrogen might be universal in breast cancer. Retinoblastomabinding protein 8 (RbBP8, also named CtIP), which we identified as a late-responsive estrogeninduced gene, was also reported to be induced by estrogen in ZR75-1 cells (Soulez \& Parker 2001), although this gene is apparently an early-responsive gene in ZR75-1 and different from the case in MCF-7. RbBP8 may be regulated by estrogen through at least partly different mechanisms or pathways in MCF-7 and ZR75-1 cells, but in any case we think the estrogen-responsiveness of RbBP8 is an interesting observation regarding breast cancer. RbBP8, identified as a binding protein to retinoblastoma, was reported to bind to
BRCA1, regulating this activity, and to have an association with the ataxia telangiectasia mutated (ATM) (Li et al. 1999, 2000). The estrogen responsiveness of this gene may implicate its involvement in the cell cycle regulation of the estrogen-dependent cells. Down-regulation of IGFBP5 by estrogen in MCF-7 cells has been reported (Huynh et al. 1996) and similar results were obtained by our cDNA microarray and Northern analysis. IGFBPs including IGFBP4 and IGFBP5 are considered to bind to IGF-I and IGF-II in the extracellular space, regulating access of IGFs to IGF receptors (reviewed by Sachdev \& Yee 2001), which is one of the most critical steps for proliferation of breast tumor cells. But the physiological meaning of the opposite regulation of IGFBP4 and IGFBP5 by estrogen is unknown. Since IGFBP5 was also reported to be localized to the nucleus (Schedlich et al. 2000), repression of IGFBP 5 by estrogen might have some influence on the functions of molecules in the nucleus such as nuclear receptors and cofactors. We newly identified c-myc promoter-binding protein 1 (MYC$\mathrm{BP} 1)$ as another estrogen-repressed gene. Since MYC-BP1 is a transcriptional repressor of the proto-oncogene c-myc (Ray \& Miller 1991), down-regulation of this gene by estrogen may bring about up-regulation of c-myc, and, in turn, the gene product $\mathrm{c}-\mathrm{Myc}$ may induce many downstream genes involved in proliferation and progression of tumor. On the other hand, there is another possibility that MYC-BP1 represses transcription of some unknown genes other than c-myc (Ghosh et al. 1999). Estrogen-responsive repression of MYC-BP1 may influence the expression levels of many genes and not only the downstream genes of c-myc.

The time courses of estrogen-responsive expression of these above-mentioned genes were analyzed by both customized cDNA microarray and Northern blot, and we obtained quite similar results for all of the genes. These observations emphasize the usefulness and reliability of the customized microarray system for analyzing the expression profiles of the estrogen-regulated genes.

We think comprehensive analysis of the effects of estrogen antagonists on breast cancer is no less important than analysis of the effects by estrogen. At present, many estrogen antagonists have been developed for anti-hormone therapy, and many reports have accumulated on the potency of 
antagonists such as tamoxifen in clinical application. Nevertheless, it has not been completely elucidated how these anti-estrogens affect the regulation of ER-target genes. Therefore, we performed microarray analysis of gene expression profiles in MCF-7 cells treated with OHT or ICI 182,780. For this experiment, we developed an upgraded custom-made cDNA microarray (named InfoArray) with a larger number of estrogenresponsive genes than the prototype microarray and supplemented it with several genes involved in metabolism of estrogen such as aromatase and estrogen sulfatase. There is no evidence that these genes are regulated by estrogen or ER, but these genes are considered to be closely associated with the physiology of estrogen-dependent breast tumors. Thus, InfoArray is a more specific version of the customized microarray for clinical application including the viewpoint of intracrinology of estrogen. To examine the anti-estrogen effects, we decided to treat the estrogen-starved MCF-7 cells with 1 or $5 \mu \mathrm{M}$ OHT or ICI 182,780 together with $10 \mathrm{nM} 17 \beta$-estradiol. These defined conditions are different from those adopted for the treatment of ZR75-1 cells in a previous report (Soulez \& Parker 2001) in that we added these antagonists together with a saturating concentration of estrogen. Our experimental design attached much importance to the purpose of gaining useful information for clinical application, for example, to screen the markers which mirror the status of breast tumors provided with estrogen from stroma but treated with anti-hormone therapy.

ICI 182,780 completely suppressed the estrogenresponsive regulation of almost all of the genes loaded on InfoArray including the genes identified through time-course analysis mentioned above, which suggests these genes are induced or repressed by estrogen through ER-dependent mechanisms or pathways. There may be no or few genes regulated by estrogen through ER-independent pathways. OHT also completely blocked the regulation of many estrogen-responsive genes, consistent with the fact that tamoxifen is considered to be an effective inhibitor of breast tumor proliferation. But, in contrast with ICI 182,780, the extent of suppression of estrogen-responsiveness by OHT was apparently much smaller than by ICI 182,780 and several genes such as MYC-BP1 and nuclear receptor interacting protein 1 appeared to show residual regulation by estrogen. Tamoxifen is recognized as a SERM (selective estrogen receptor modulator) and has been demonstrated to work as an agonist in some promoter contexts and some organs. Our results concerning the effects of OHT suggest that some genes in MCF-7 possess an unidentified estrogen-responsive regulation mechanism on which tamoxifen acts as a partial agonist.

We think InfoArray is one of the most useful tools to examine the potency and specific effects of other estrogen antagonists, such as raloxifene and newly-designed anti-estrogen drugs, and estrogenlike endocrine disrupters on breast cancer. Using InfoArray and several cell lines, we may be able to develop an assay system which can evaluate the dose effects of diverse estrogen-like compounds including anti-hormones, and find the markers to discriminate the effects of certain compounds from others with high specificity.

As is generally known, the effects and functions of estrogen are not limited to the physiology of hormone-dependent cancer and there have been several reports concerning the effects of estrogen on organs and cells other than breast cancer. For example, in glomerular mesangial cells of the kidney, estrogen suppressed collagen synthesis (Dubey \& Jackson 2001), and in ER-positive human melanoma cells the production of interleukin-8 was inhibited by estrogen (Kanda \& Watanabe 2001).

We were intrigued as to how potent the InfoArray is for evaluating estrogen-responsiveness of cells derived from organs other than breast. In other words, we thought it important to investigate how many genes among the gene set loaded on InfoArray would also exhibit regulation by estrogen in other cells. Therefore, using InfoArray, we analyzed the gene expression profiles in twelve cells other than MCF-7 cells treated with estrogen. Unfortunately, all of the twelve cells exhibited much lower responsiveness to estrogen treatment than MCF-7 cells, so we could not find any gene expression patterns that were characteristic or available to distinguish the organ- or tissue-specific responsiveness to estrogen. But some genes were suggested to be induced or repressed by estrogen in one cell line or several cell lines. Further analysis will be needed to clarify the functions of these genes regarding the estrogen-responsiveness of each cell line or organ.

We are now trying gene expression profiling of breast cancer tissues from patients using InfoArray. 
This analysis will also provide useful information for our goal, but in the case of analysis using tissue samples there are a lot of limitations regarding design of experimental conditions such as duration and dosage of estrogen and/or anti-estrogen treatment, treatment with newly-developed drugs which are not approved yet for clinical application, and exposure to hormone-like endocrine disrupters. Gene expression profiling analysis of both tissue samples and cell lines cultured in diverse conditions using the same cDNA microarray system with narrowed-down estrogen-responsive genes will complement the advantages and disadvantages of each type of analysis, and it will contribute to clarification of the physiology of breast cancer and to the establishment of the best clinical diagnosis.

\section{Acknowledgements}

We thank Ms Akiyo Yamashita for her excellent technical assistance, Dr Masakazu Toi (Tokyo Metropolitan Komagome Hospital) for providing the tamoxifen-resistant breast cancer cell line MCF-7 c9, and Dr Kei Nakachi for his valuable suggestions and advice. This study was supported in part by Grants-in-Aid from the Ministry of Education, Culture, Sports, Science and Technology of Japan for Cancer Research, from the Ministry of Health, Labor and Welfare of Japan for Scientific Research Expenses for Health and Welfare Programs and the Foundation for the Promotion of Cancer Research and for the Second-Term Comprehensive 10-Year Strategy for Cancer Control, from the Ministry of the Environment of Japan for the Pollution Control Technology, and from the Ministry of Economy, Trade and Industry of Japan for Research Projects for Smaller Enterprises.

\section{References}

Anderson E, Clarke RB \& Howell A 1998 Estrogen responsiveness and control of normal human breast proliferation. Fournal of Mammary Gland Biology and Neoplasia $323-35$.

Arimura G, Tashiro K, Kuhara S, Nishioka T, Ozawa R \& Takabayashi J 2000 Gene responses in bean leaves induced by herbivory and by herbivore-induced volatiles. Biochemical and Biophysical Research Communications 277 305-310.

Augereau P, Miralles F, Gavaillès V, Gaudelet C, Parker M \& Rochefort H 1994 Characterization of the proximal estrogen-responsive element of human cathepsin D gene. Molecular Endocrinology 8 693-703.
Brown AMC, Jeltsch JM, Roberts M \& Chambon P 1984 Activation of pS2 gene transcription is a primary response to estrogen in the human breast cancer cell line MCF-7. PNAS 816344 6348.

Chomczynski P \& Sacchi N 1987 Single-step method of RNA isolation by acid guanidinium thiocyanate-phenol-chloroform extraction. Analytical Biochemistry 162 156-159.

Ciocca DR \& Fanelli MA 1997 Estrogen receptors and cell proliferation in breast cancer. Trends in Endocrinology and Metabolism 8 313-321.

Dubey RK \& Jackson AEK 2001 Estrogen-induced cardiorenal protection: potential cellular, biochemical, and molecular mechanisms. American Fournal of Physiology and Renal Physiology 280 F365-F388.

Eisen MB, Spellman PT, Brown PO \& Botstein D 1998 Cluster analysis and display of genome-wide expression patterns. PNAS 95 14863-14868.

Finlin BS, Gau C-L, Murphy GA, Shao H, Kimel T, Seitz RS, Chiu Y-F, Botstein D, Brown PO, Der CJ, Tamanoi F, Andres DA \& Perou CM 2001 RERG is a novel ras-related, estrogen-regulated and growth-inhibitory gene in breast cancer. Fournal of Biological Chemistry 276 42259-42267.

Fusco C, Reymond A \& Zervos AS 1998 Molecular cloning and characterization of a novel retinoblastoma-binding protein. Genomics 51 351-358.

Gaugitsch HW, Prieschl EE, Kalthoff F, Huber NE \& Baumruker T 1992 A novel transiently expressed integral membrane protein linked to cell activation: molecular cloning via the rapid degradation signal AUUUA. Fournal of Biological Chemistry 267 11267-11273.

Ghosh AK, Steele R \& Ray RB 1999 Functional domains of c-myc promoter binding protein 1 involved in transcriptional repression and cell growth regulation. Molecular and Cellular Biology 19 2880-2886.

Ghosh MG, Thompson DA \& Weigel RJ 2000 PDZK1 and GREB1 are estrogen-regulated genes expressed in hormone-responsive breast cancer. Cancer Research $606367-6375$.

Gruvberger S, Ringnér M, Chen Y, Panavally S, Lao HS, Borg Å, Fernö M, Peterson C \& Meltzer PS 2001 Estrogen receptor status in breast cancer is associated with remarkably distinct gene expression patterns. Cancer Research 61 5979-5984.

Hall JM, Couse JF \& Korach KS 2001 The multifaceted mechanisms of estradiol and estrogen receptor signaling. Fournal of Biological Chemistry 276 36869-36872.

Hayashi S-I, Imai K, Suga K, Kurihara T, Higashi Y \& Nakachi K $1997 a$ Two promoters in expression of estrogen receptor messenger RNA in human breast cancer. Carcinogenesis $\mathbf{1 8}$ 459-464.

Hayashi S-I, Hajiro-Nakanishi K, Makino Y, Eguchi H, Yodoi J \& Tanaka H. $1997 b$ Functinal modulation of estrogen receptor by redox state with reference to thioredoxin as a mediator. Nucleic Acids Research 25 4035-4040.

Huynh H, Yang X-F \& Pollak M 1996 A role for insulin-like growth factor binding protein 5 in the antiproliferative action of the antiestrogen ICI 182,780. Cell Growth and Differentiation 7 1501-1506.

Jakowlew SB, Breathnach R, Jeltsch JM, Masiakowski P \& Chambon $\mathrm{P} 1984$ Sequence of the $p S 2 \mathrm{mRNA}$ induced by estrogen in the human breast cancer cell line MCF-7. Nucleic Acids Research 12 2861-2878.

Kanda N \& Watanabe S 200117 Beta-estradiol, progesterone, and dihydrotestosterone suppress the growth of human melanoma by inhibiting interleukin-8 production. Fournal of Investigative Dermatology $117274-283$.

Kiefer MC, Ioh RS, Bauer DM \& Zapf J 1991a Molecular cloning of a new human insulin-like growth factor binding protein. Biochemical and Biophysical Research Communications 176 219-225. 
Kiefer MC, Masiarz FR, Bauer DM \& Zapf J $1991 b$ Identification and molecular cloning of two new $30-\mathrm{kDa}$ insulin-like growth factor binding proteins isolated from adult human serum. Fournal of Biological Chemistry 266 9043-9049.

Kikuno R, Nagase T, Ishikawa K, Hirosawa M, Miyajima N, Tanaka A, Kotani H, Nomura N \& Ohara O 1999 Prediction of the coding sequences of unidentified human genes. XIV. The complete sequences of 100 new cDNA clones from brain which code for large proteins in vitro. DNA Research 6 197-205.

Lapidus RG, Nass SJ \& Davidson NE 1988 The loss of estrogen and progesterone receptor gene expression in human breast cancer. Fournal of Mammary Gland Biology and Neoplasia 3 85-94.

Li S, Chen P-L, Subramanian T, Chinnadurai G, Tomlinson G, Osborne CK, Sharp ZD \& Lee W-H 1999 Binding of CtIP to the BRCT repeats of BRCAl involved in the transcription regulation of p21 is disrupted upon DNA damage. Fournal of Biological Chemistry 274 11334-11338.

Li S, Ting NSY, Zheng L, Chen P-L, Ziv Y, Shiloh Y, Lee E, Y-H \& Lee W-H 2000 Functional link of BRCAl and ataxia telangiectasia gene product in DNA damage response. Nature $\mathbf{4 0 6}$ 210-215.

McGuire WL 1978 Hormone receptors: their role in predicting prognosis and response to endocrine therapy. Seminars in Oncology $\mathbf{5}$ $428-433$.

Mandlekar S \& Kong A-NT 2001 Mechanisms of tamoxifen-induced apoptosis. Apoptosis 6 469-477.

Masiakowski P, Breathnach R, Bloch J, Gannon F, Krust A \& Chambon P 1982 Cloning of cDNA sequences of hormoneregulated genes from the MCF-7 human breast cancer cell line. Nucleic Acids Research 10 7895-7903.

Nadal A, Ropero AB, Laribi O, Maillet M, Fuentes E \& Soria B 2000 Nongenomic actions of estrogens and xenoestrogens by binding at a plasma membrane receptor unrelated to estrogen receptor $\alpha$ and estrogen $\beta$. PNAS 97 11603-11608.

Nakajima-Iijima S, Hamada H, Reddy P \& Kakunaga T 1985 Molecular structure of the human cytoplasmic beta-actin gene: interspecies homology of sequences in the introns. PNAS $\mathbf{8 2}$ 6133-6137.

Pietras R \& Szego CM 1977 Specific binding sites for oestrogen at the outer surfaces of isolated endometrial cells. Nature 265 69-72.

Pike M, Spicer D, Dahmoush L \& Press M 1993 Estrogens, progesterones, normal breast cell proliferation and breast cancer risk. Epidemiologic Reviewes 15 17-35.

Qin C, Singh P \& Safe S 1999 Transcriptional activation of insulinlike growth factor-binding protein- 4 by $17 \beta$-estradiol in MCF-7 cells: role of estrogen receptor-Spl complexes. Endocrinology 140 2501-2508.

Ray R \& Miller DM 1991 Cloning and characterization of a human c-myc promoter-binding protein. Molecular and Cellular Biology 11 2154-2161.

Sachdev D \& Yee D 2001 The IGF system and breast cancer. Endocrine-Related Cancer 8 197-209.
Saji S, Okumura N, Eguchi H, Nakashima S, Suzuki A, Toi M, Nozawa Y, Saji S \& Hayashi S-I 2001 MDM2 enhances the function of estrogen receptor $\alpha$ in human breast cancer cells. Biochemical and Biophysical Research Communications 281 259-265.

Schedlich LJ, Page SLL, Firth SM, Briggs LJ, Jans DA \& Baxter RC 2000 Nuclear import of insulin-like growth factor-binding protein- 3 and -5 is mediated by the importin $\beta$ subunit. Fournal of Biological Chemistry 275 23462-23470.

Shoker BS, Jarvis C, Sibson DR, Walker C \& Sloane JP 1999 Oestrogen receptor expression in the normal and pre-cancerous breast. Fournal of Pathology 188 237-244.

Sørlie T, Perou CM, Tibshirani R, Aas T, Geisler S, Johnsen H, Hastie T, Eisen MB, van de Rijn M, Jeffrey SS, Thorsen T, Quist H, Matese JC, Brown PO, Botstein D, Lønning PE \& BørresenDale A-L 2001 Gene expression patterns of breast carcinomas distinguish tumor subclasses with clinical implications. PNAS 98 10869-10874.

Soulez M \& Parker MG 2001 Identification of novel oestrogen receptor target genes in human ZR75-1 breast cancer cells by expression profiling. Fournal of Molecular Endocrinology 27259 274.

Tanimoto K, Eguchi H, Yoshida T, Hajiro-Nakanishi K \& Hayashi S-I 1999 Regulation of estrogen receptor $\alpha$ gene mediated by promoter B responsible for its enhanced expression in human breast cancer. Nucleic Acids Research 27 903-909.

Thenot S, Charpin M, Bonnet S \& Cavailles V 1999 Estrogen receptor cofactors expression in breast and endometrial human cancer cells. Molecular and Cellular Endocrinology 156 85-93.

Toi M, Harris AL \& Bicknell R 1993 cDNA transfection followed by the isolation of a MCF-7 breast cell line resistant to tamoxifen in vitro and in vivo. British Fournal of Cancer 68 1088-1096.

van't Veer LJ, Dai H, van de Vijver MJ, He YD, Hart AA, Mao M, Peterse HL, van der Kooy K, Marton MJ, Witteveen AT, Schreiber GJ, Kerkhoven RM, Roberts G, Linsley PS, Bernards R \& Friend SH 2002 Gene expression profiling predicts clinical outcome of breast cancer. Nature 415 530-536.

West M, Blanchette C, Dressman H, Huang E, Ishida S, Spang R, Zuzan H, Olson JA, Marks JR \& Nevins JR 2001 Predicting the clinical status of human breast cancer by using gene expression profiles. PNAS 98 11462-11467.

Westley B \& Rochefort H 1980 A secreted glycoprotein induced by estrogen in human breast cancer cell lines. Cell 20 353-362.

Yoshida T, Eguchi H, Nakachi K, Tanimoto K, Higashi Y, Suemasu K, Iino Y, Morishita Y \& Hayashi S-I 2000 Distinct mechanisms of loss of estrogen receptor $\alpha$ gene expression in human breast cancer: methylation of the gene and alteration of tras-acting factors. Carcinogenesis 21 2193-2201.

Received in final form 22 March 2002 Accepted 9 May 2002 